\title{
Loss Performance Analysis of an Isolated Power Supply for Ultrafast Tracking Converters
}

Nguyen-Duy, Khiem; Knott, Arnold; Andersen, Michael A. E.

Published in:

Proceedings of IEEE International Power Electronics and Application Conference and Exposition

Link to article, DOI:

10.1109/PEAC.2014.7038095

Publication date:

2014

Link back to DTU Orbit

Citation $(A P A)$ :

Nguyen-Duy, K., Knott, A., \& Andersen, M. A. E. (2014). Loss Performance Analysis of an Isolated Power Supply for Ultrafast Tracking Converters. In Proceedings of IEEE International Power Electronics and Application Conference and Exposition (pp. 1543-1548 ). IEEE. https://doi.org/10.1109/PEAC.2014.7038095

\section{General rights}

Copyright and moral rights for the publications made accessible in the public portal are retained by the authors and/or other copyright owners and it is a condition of accessing publications that users recognise and abide by the legal requirements associated with these rights.

- Users may download and print one copy of any publication from the public portal for the purpose of private study or research.

- You may not further distribute the material or use it for any profit-making activity or commercial gain

- You may freely distribute the URL identifying the publication in the public portal 


\title{
Loss Performance Analysis of an Isolated Power Supply for Ultrafast Tracking Converters
}

\author{
Khiem Nguyen-Duy, Arnold Knott, and Michael A. E. Andersen \\ Department of Electrical Engineering, Technical University of Denmark \\ 2800 Kongens Lyngby, Denmark \\ knduy@elektro.dtu.dk, akn@elektro.dtu.dk,ma@elektro.dtu.dk
}

\begin{abstract}
This paper presents the loss performance analysis of an isolated power supply that is designed for ultra-fast tracking converters. The results of the analysis provide insights into the operation of the proposed power supply, how each physical component contributes to the total loss, and how its efficiency may be further improved.
\end{abstract}

Keywords-Dc-dc power converters, loss measurement, magnetic losses, switching loss.

\section{INTRODUCTION}

Power supply designed for fast output voltage transient applications should meet certain requirements regarding their input-to-output parasitic capacitance. Specifically, the circuit input-to-output capacitance should be as low as possible in order to mitigate the transmission of common mode noise generated by the fast output voltage transients [1]-[4]. First, [1] proposed an isolated power supply with a power rating of $36 \mathrm{~V} / 5 \mathrm{~W}$ and a ring core transformer with an inter-winding capacitance of $1 \mathrm{pF}$. Next, [2], [3], and [4] introduced a prototype using the same topology as in [1], but the power rating was increased to $60 \mathrm{~V} / 300 \mathrm{~W}$ and the proposed transformer had an inter-winding capacitance of $10 \mathrm{pF}$.

Reference [2] and [3] also described the circuit operation, control, and general structure of the proposed transformer in addition to the circuit topology. However, the loss performance analysis of the converters had not been addressed. The topology introduced in [1] and studied in [2][3] is shown in Fig. 1.

This paper addresses the loss performance analysis of the converter proposed in [1]-[4]. The detail of the circuit operation will not be covered in this paper; they can be found in [2] and [3]. Instead, this paper will focus on the loss performance of the converter prototype proposed in [3]. It will be shown that the loss calculation matches well with the experiments. The results suggest how each physical component contributes to the total loss, and how its efficiency may be further improved.

\section{CONVERTER OPERATION AND ITS INFLUENCE ON INDIVIDUAL LOSS}

The converter proposed in [2], [3] and studied in this paper for its loss performance is shown in Fig. 1. The specification of the prototype is shown in Table I. It consists of a full-bridge

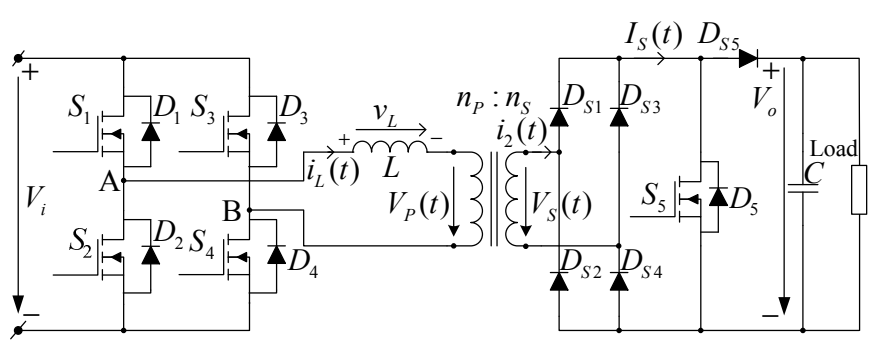

Fig. 1. The topology of the proposed power supply.

TABLE I. Prototype SPECIFiCATion

\begin{tabular}{|l|c|}
\hline Input voltage & $400 \mathrm{~V}$ \\
\hline Output voltage & $60 \mathrm{~V}$ \\
\hline Output current & $5 \mathrm{~A}$ \\
\hline Maximum output power & $300 \mathrm{~W}$ \\
\hline Leakage inductance & $170 \mu \mathrm{H}$ \\
\hline
\end{tabular}

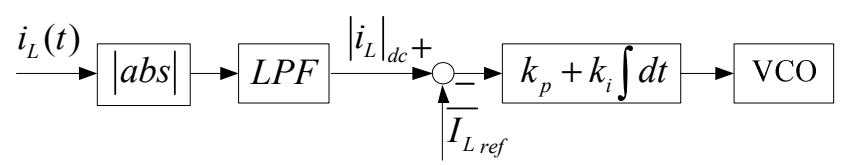

(a)

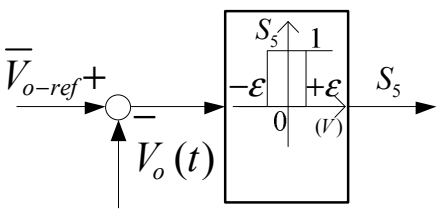

(b)

Fig. 2. Control block diagram. (a) Average current mode control in the primary side and (b) hysteresis control in the secondary side.

on the primary side and a proposed shunt regulator on the secondary side. The two sides are linked by a transformer that has an extremely low interwinding capacitance of $10 \mathrm{pF}$. This makes the power supply suitable for supplying energy to applications with fast changes in voltage such as the ultrafast tracking converters. Because of the transformer winding structure that minimizes the interwinding capacitance, the resulting leakage inductance $L$ is large, which is $170 \mu \mathrm{H}$ [3]. This inductance is used as the main energy storage component to transfer current from the primary to the secondary side. There is no external inductor added to the circuit structure except for the leakage inductor of the proposed transformer. 


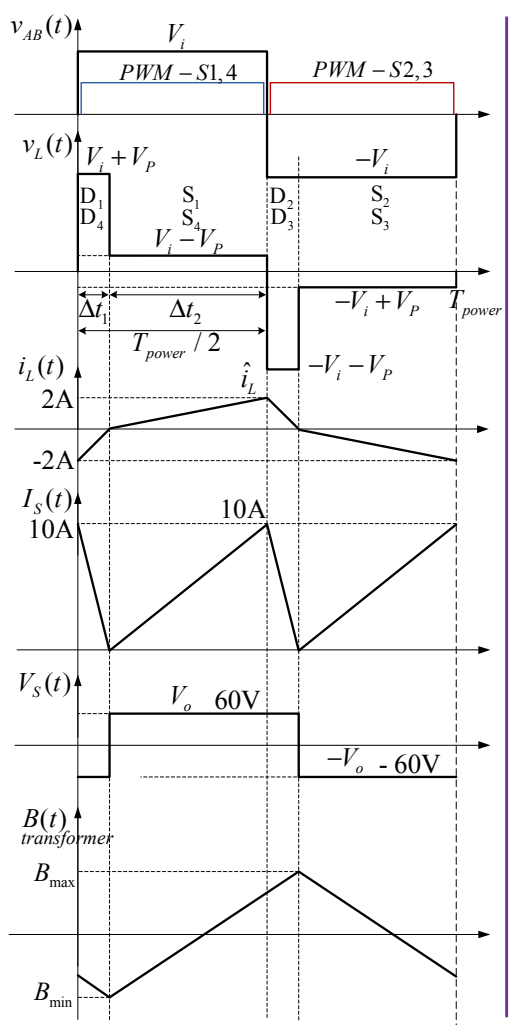

(a)

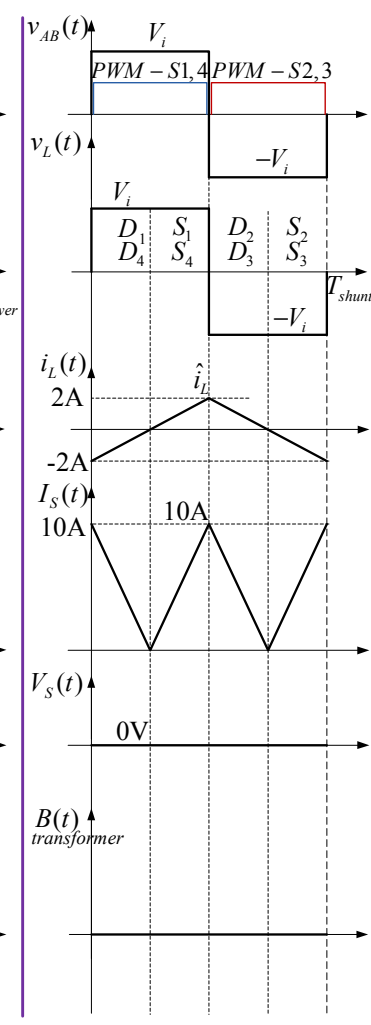

(b)

Fig. 3. Analytical waveforms when the converter operates in: (a) Power mode and (b) shunt mode.

The converter circuit operation is briefly sated in this section. The detail can be found in Section VI of [3]. It is very important to understand different operation modes of the proposed converter in order to analyze the individual loss.

There are two control loops whose block diagrams are shown in Fig. 2. The secondary side controller regulates the output voltage to be constant at $60 \mathrm{~V}$. The output voltage is sensed by a voltage divider and compared to a hysteresis reference to switch ON and OFF the shunt switch $S_{5}$.

When $S_{5}$ is OFF, the converter operates in its power mode, which is shown in Fig. 3(a); the output voltage increases because the output current $I_{S}(t)$ supplies energy to the load. Vice versa, when $S_{5}$ is ON, shunting the secondary side, the converter operates in its shunt mode (see Fig. 3(b)); the output voltage decreases because the secondary current $I_{S}(\mathrm{t})$ is isolated from the load. On the primary side control, the primary side current $i_{L}$ is sensed. It is rectified and filtered to produce a rectified-dc value. This value is then compared to a rectified-dc reference and processed by an analog proportional-integrator (PI) controller. The output of the PI controller is fed to a voltage-controlled oscillator (VCO) that will automatically adjust the switching frequency to keep the rectified primary dc current to be constant at $1 \mathrm{~A} \mathrm{dc}$. The duty cycle of the primary switches is regulated at $50 \%$. With a turns ratio of $5: 1$, the rectified dc current at the secondary side is controlled at $5 \mathrm{~A} \mathrm{dc}$.

When the converter operates in power mode, the output power is $300 \mathrm{~W}$ because the output current $I_{S}(t)$ which has a dc value of $5 \mathrm{~A}$ is supplying the load whose voltage is regulated at $60 \mathrm{~V} \mathrm{dc}$. On the other hand, when the converter operates in shunt mode, the output current $I_{S}(t)$ is isolated from the load, circulating through $S_{5}$; the output power is zero. The converter is constantly switching between the power mode and shunt mode. It depends on the output power level to determine how long the converter is operating in each mode. For example, if the converter is desired to deliver $300 \mathrm{~W}$ at the output, then it will fully operate in power mode. If the converter is desired to shut down the output power, or to not deliver any power at all, then the converter will entirely operate in shunt mode. The higher the output power (closer to $300 \mathrm{~W}$ ) the longer time the converter operates in power mode.

Therefore, if the converter outputs a power of $P_{\text {out }}$, then the duty cycle in which the converter operates in power mode will be:

$$
d_{\text {power }}=\frac{P_{\text {out }}}{P_{\max }}
$$

where $P_{\max }$ is the maximum output power of the converter. In this design, $P_{\max }$ is equal to $300 \mathrm{~W}$. Likewise, the duty cycle in which the converter operates in shunt mode is:

$$
d_{\text {shunt }}=\frac{P_{\max }-P_{\text {out }}}{P_{\max }}=1-d_{\text {power }}
$$

Duty cycle $d_{\text {shunt }}$ is also the duty cycle of turning-on shunt switch $S_{5}$. It is noticed that $d_{\text {power }}$ and $d_{\text {shunt }}$ changes with output power.

During shunt mode, the switching frequency of the primary side switches, $f_{\text {shunt }}$, is $307 \mathrm{kHz}$. During power mode, the switching frequency, $f_{\text {power }}$, is $124 \mathrm{kHz}$. The detail of the derivation of the switching frequency can be found in Section VI of [3].

The switching between the two operation modes affect different individual loss in a different way because the current waveforms and switching frequency are switched between two modes. The losses that are affected by the switching of the operation modes are the switching losses of the primary side switches, the core loss and copper loss of the transformer, and the losses in $D_{S 5}$ and $S_{5}$. For convenience, for the losses calculation involving the switching frequency, the normalized switching frequency is introduced:

$$
f_{\text {norm }}=d_{\text {power }} f_{\text {power }}+d_{\text {shunt }} f_{\text {shunt }} .
$$

It is also noticed that $f_{\text {norm }}$ changes with the change in output power. For example, $f_{\text {norm }}=f_{\text {power }}$ when $P_{\text {out }}=P_{\max }$, and $f_{\text {norm }}=f_{\text {shunt }}$ when $P_{\text {out }}=0$.

On the contrary, the transition between the two operation modes does not affect the conduction losses of the primary side switches $S_{1}-S_{4}$ and the conduction loss of the diode 
bridge consisting of $D_{S I}-D_{S 4}$. This is because the currents flowing through these devices do not change their root-meansquare value regardless of the operation mode as shown in Fig. 3. This will also be observed in the next section from the formulas used to calculate these conduction losses.

\section{LOSS PERFORMANCE ANALYSIS}

\section{A. Losses on the Primary Side Switches $S_{I}-S_{4}$}

The power dissipation of primary side MOSFETs consists mainly of conduction loss and switching loss:

$$
P_{d_{-} \text {total }}=P_{d_{-} \text {cnd }}+P_{d_{-} s w},
$$

where $P_{d_{-} \text {total }}$ is the total loss in the four primary switches, $P_{d_{-} \text {cnd }}$ is the total conduction loss, and $P_{d_{-} s w}$ is the total switching loss. At any instant of a full switching period, there are maximum two MOSFETs conducting. Therefore, the conduction power loss in one primary side switch, $P_{\text {cond-1MOS }}$, is:

$$
P_{\text {cond }-1 M O S}=R_{D S-o n} I_{r m s}^{2}=R_{D S-o n}\left(\frac{I_{p e a k}}{\sqrt{3}} \sqrt{d}\right)^{2}
$$

where $I_{r m s}$ is the root-mean-square value of the current flowing through a primary switch during a period, $I_{\text {peak }}$ is the peak current value, $I_{\text {peak }}=2 \mathrm{~A}$, and $d$ is the duty cycle of the current, $d=0.5$ (see Fig. 4). $R_{D S-o n}$ is the on resistance of the drain to source of the MOSFET. $R_{D S-o n}=1.1 \Omega$ at $65^{\circ} \mathrm{C}$ and a gate-source voltage of $10 \mathrm{~V}$. The power MOSFET on the primary side uses part IRF840 from Vishay whose datasheet can be found in [5].

From (5), the conduction loss does not change regardless of the operation mode in which the converter is operating. This is because the root-mean-square value of the current is the same in both modes. The total conduction loss in the whole four primary side MOSFETs, $P_{d_{-} \text {cnd }}$, is therefore:

$$
P_{d_{-} \text {cnd }}=4 P_{\text {cond }-1 M O S}=2.93 \mathrm{~W} \text {. }
$$

At the turning-on transitions of the MOSFETS, the transitions are made from the body diode in the same MOSFET to its channel. For example, the transition are from $D_{1}$ to $S_{1}, D_{2}$ to $S_{2}, D_{3}$ to $S_{3}$, and $D_{4}$ to $S_{4}$. Because the MOSFETs are conducting, the voltages across them are zero. It is also observed that the currents conducting through them are crossing the zero value. This characteristic can be observed from Fig. 4. For this reason, there is no switching loss in the turn-on transitions.

The total switching loss during turn off in the whole four MOSFET is:

$$
P_{d_{-} s w}=4 P_{s w-1 M O S}=4 E_{o f f} f_{s w}=2 V_{i} I_{\text {peak }} t_{f} f_{\text {norm }} \text {, }
$$

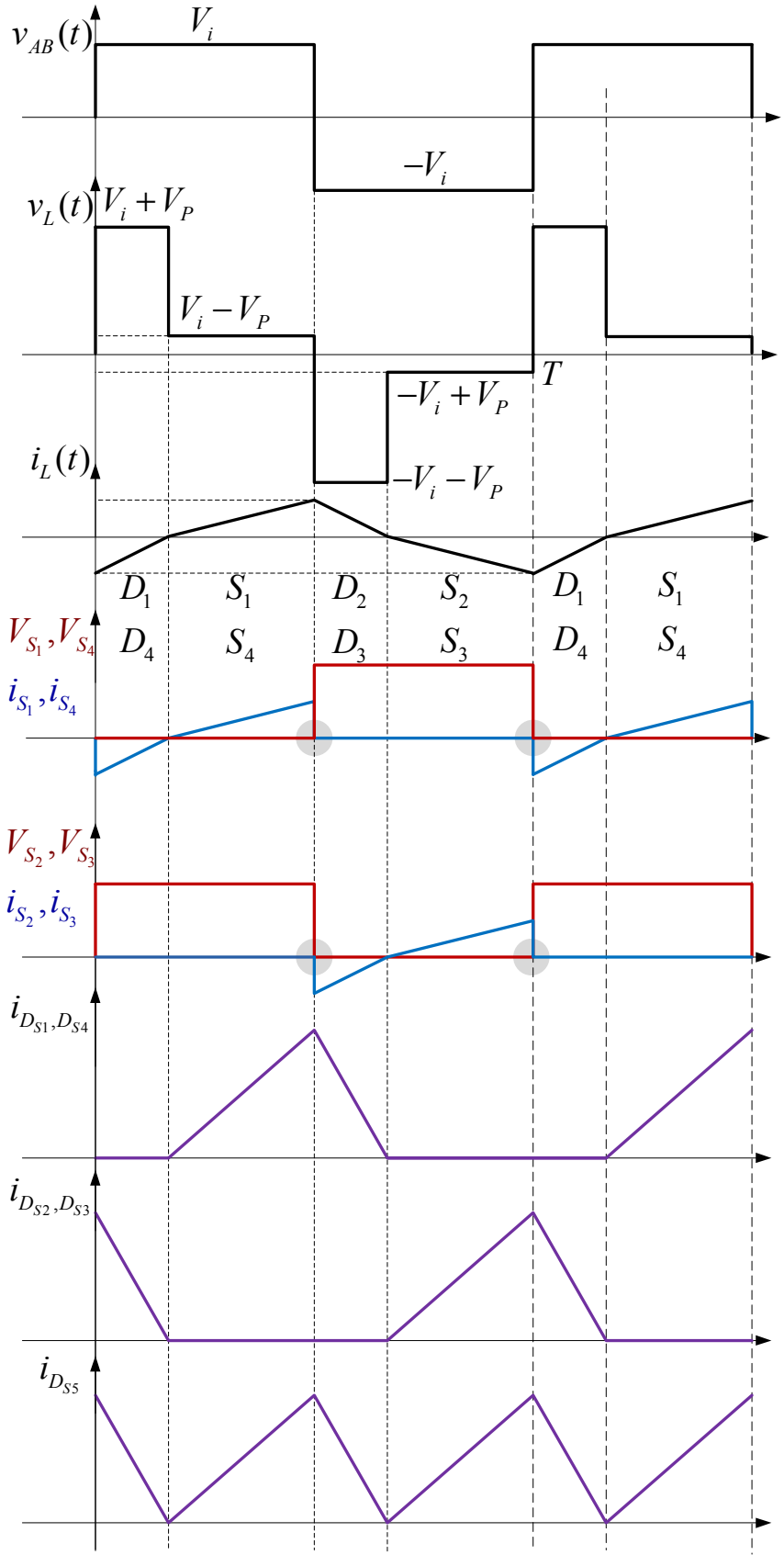

Fig. 4. The current and voltage waveforms across power switches and diodes.

where $E_{\text {off }}$ is the energy loss during turn-off transients, $I_{\text {peak }}$ is the peak current value during turn-off, and $t_{f}$ is the fall time duration provided by the datasheet of the MOSFET, $t_{f}=30$ ns.

\section{B. Losses on the Secondary Side}

1) Loss in the diode bridge $D_{S I}-D_{S 4}$

The diode bridge uses part MBR10T100 from Vishay [6]. The loss in one diode, $P_{1-D}$, is: 


$$
P_{1-D}=V_{F M} I_{D-\text { avg }}+R_{D} I_{D-r m s}^{2},
$$

where $V_{F M}$ is the forward voltage drop. Its value is $V_{F M}=0.57$ $\mathrm{V}$ at $125^{\circ} \mathrm{C}$ and $0.71 \mathrm{~V}$ at $25^{\circ} \mathrm{C}$. The value of $V_{F M}$ at $65^{\circ} \mathrm{C}$ is used in the calculation because the prototype is attached to two sufficiently large heat sinks that are expected to keep the temperature rise of the power switches to be within $40^{\circ} \mathrm{C}$ Taking the linear interpolation of $V_{F M}$ yields $V_{F M}=0.65 \mathrm{~V}$. $R_{D}$ is approximated to be equal to the slope the diode currentvoltage curve at the average operating forward current of $5 \mathrm{~A}$. From the data-sheet of the part used, the value of $R_{D}$ is 0.02 $\Omega$. This value is taken into the loss estimation. Meanwhile, $I_{D-\text { avg }}$ is the average value of the current flowing through each diode, $I_{D-\text { avg }}=2.5 \mathrm{~A} . \quad I_{D-r m s}$ is the root-mean-square value of the diode current, $I_{D-r m s}=\left(I_{D-\text { peak }} / \sqrt{3}\right) \sqrt{d_{D}}$.

The duty cycle of the triangular current flowing through one diode is $d_{D}=0.5$. The peak diode current value is $I_{D-\text { peak }}=$ $10 \mathrm{~A}$. Therefore, $I_{D-r m s}=4.1 \mathrm{~A}$.

Substituting these values to (8) yields $P_{1-D}=1.96 \mathrm{~W}$. The total loss in the four diodes in the rectifier bridge is:

$$
P_{D-\text { bridge }}=4 P_{1-D}=7.83 \mathrm{~W} .
$$

It is noted that there is no reverse-recovery loss in the diode bridge since the diode parts are Schottky-effect diodes.

\section{2) Loss in forward diode $D_{S 5}$}

Forward diode $D_{S 5}$ also uses part MBR10T100 from Vishay [6]. The forward average current flowing through diode $D_{S S}$ is: $I_{D S 5 \text {-avg }}=5 \mathrm{~A}$ (see Fig. 4). The root mean square of that current is: $I_{D S 5-r m s}=\left(I_{D S 5-\text { peak }} / \sqrt{3}\right) \sqrt{d_{D S 5}}=5.8 \mathrm{~A}$, where $d_{D S 5}$ is the duty cycle of the current, $d_{D S 5}=1, I_{D S 5-\text { peak }}$ is the current peak value, $I_{D S 5-\text { peak }}=10 \mathrm{~A}$. The forward voltage drop is $V_{F M}=0.65 \mathrm{~V}$ at $65^{\circ} \mathrm{C}$. The value of $R_{D}$ is 0.02 $\Omega$.

The loss in forward diode $D_{S 5}$ is therefore:

$$
P_{D S 5}=V_{F M} I_{D S 5-\text { avg }}+R_{D} I_{D S 5-r m s}^{2}=3.92 \mathrm{~W} .
$$

\section{3) Loss in shunt MOSFET $S_{5}$}

Shunt MOSFET $S_{5}$ uses part IRF540 from Vishay [7], which has an on-resistance of $0.096 \Omega$ at $65^{\circ} \mathrm{C}$ at a gatesource voltage of $10 \mathrm{~V}$. The conduction loss is:

$$
P_{D S 5}=R_{S_{5}-D S-o n} I_{S_{5}-r m s}^{2}=3.2 \mathrm{~W},
$$

where $I_{S_{5}-r m s}$ is the root-mean-square value of the current flowing through $S_{5}$ during shunt mode.

Because the switching frequency of $S_{5}$ is small, the switching loss is small compared to the conduction loss and is ignored.

\section{Losses in the Transformer}

TABle II. Parameters of Magnetic Core and Winding Geometries of THE TRANSFORMER

\begin{tabular}{|l|l|}
\hline Material & $\mathrm{N} 87$ \\
\hline Dimension & $36 \mathrm{~mm} \times 23 \mathrm{~mm} \times 15 \mathrm{~mm}$ \\
\hline Turns ratio & $55: 11$ \\
\hline Primary winding & Litz-wire $60 \times 0.2 \mathrm{~mm}$ \\
\hline Secondary winding & Copper $1 \mathrm{~mm}$ diameter \\
\hline Effective cross sectional area & $A_{e}=95.89 \mathrm{~mm}^{2}$ \\
\hline Effective volume & $V_{e}=8597 \mathrm{~mm}^{3}$ \\
\hline
\end{tabular}

TABLE III. Fitting Coefficient of the Core Loss Calculation

\begin{tabular}{|c|c|}
\hline$K_{F e}$ & 25.2156 \\
\hline$x$ & 1.2786 \\
\hline$y$ & 2.5850 \\
\hline$f_{e q}$ & $0.81 f$ \\
\hline
\end{tabular}

The parameters of the magnetic core and material, and turns ratio are listed in Table II. The parameters of the magnetic core geometries and material characteristic can be found in [8] and [9], respectively. The detailed description of the transformer structure can be found in [3] and it will not be covered again in this paper.

According to the Modified Steinmetz Equation (MSE) reported in [10]-[16], the core loss per volume, $P_{\text {Fe-rel }}$, is:

$$
P_{F e_{-} r e l}=K_{F e} f_{e q}^{x-1} \hat{B}^{y} f,
$$

where $K_{F e}, x$, and $y$ are dependent on the core material. $K_{F e}$, $x$, and $y$ are based on Steinmetz equation and they can be extracted from curve-fitting the experimental ferrite loss in the datasheet in [9]. $\hat{B}$ is the peak flux density, $f$ is the switching frequency, and $f_{e q}$ is the equivalent switching frequency. According to [10], $f_{e q}$ is related to the switching frequency $f$ and the shape of the flux density waveform by

$$
f_{e q}=\frac{2}{\Delta B^{2} \pi^{2}} \int_{0}^{T}\left(\frac{d B}{d t}\right)^{2} d t
$$

where $\Delta B$ is the peak-to-peak value of the flux density, $T$ is the period of the excitation. The equivalent switching frequency, $f_{e q}$, is equal to $f$ if sinusoidal excitation is used.

In this converter, the excitation is based on a triangular wave form as shown in the bottom of Fig. 3. From (13), we have

$$
\begin{aligned}
f_{e q} & =\frac{2}{(2 \hat{B})^{2} \pi^{2}}\left(\int_{0}^{T / 2}\left(\frac{2 \hat{B}}{T / 2}\right)^{2} d t+\int_{T / 2}^{T}\left(\frac{2 \hat{B}}{T / 2}\right)^{2} d t\right) \\
& =\frac{2}{4 \hat{B}^{2} \pi^{2}}\left(\left.\frac{16 \hat{B}^{2}}{T^{2}} t\right|_{t=0} ^{t=T / 2}+\left.\frac{16 \hat{B}^{2}}{T^{2}} t\right|_{t=T / 2} ^{t=T}\right) \\
& =\frac{8}{\pi^{2} T}=\frac{8}{\pi^{2}} f=0.81 f .
\end{aligned}
$$


The results of these fitting coefficients are shown in Table III, where $P_{F e \text { rel }}$ is in watt per cubic-meter.

The calculated core loss is $P_{F e}=2.39 \mathrm{~W}$. The calculated copper loss is $2.13 \mathrm{~W}$ in power mode and $2.97 \mathrm{~W}$ in shunt mode.

\section{EXPERIMENTAL RESULTS}

The prototype of the proposed power supply is shown in Fig. 5. Fig. 6 shows the transient response from power mode to shunt mode. In a similar way, the transient from shunt mode to power mode is shown in Fig. 7. The value of the output voltage threshold, $\varepsilon$, is set to $0.5 \mathrm{~V}$. It can be observed that, both the inductor current and the output voltage are well regulated at their desired steady state values, which are $2 \mathrm{~A}$ peak and $60 \mathrm{~V} \mathrm{dc}$, respectively. The transient of the current from power mode to shunt mode and vice versa finishes within about $30 \mu \mathrm{s}$ and $40 \mu \mathrm{s}$, respectively. The time needed for the inductor current to settle is mainly determined by the dynamic of the average current control scheme described in Fig. 2(a). Nevertheless, the transient and steady state are both stable and satisfactory. The behavior of the circuit matches accurately with the aforementioned circuit analysis.

The calculated break down loss is shown in Fig. 8. As can be seen, the loss in the primary side H-bridge accounts more than $60 \%$ of the loss at low output power and around $40 \%$ at high output power. The loss contributed by the diode bridge is constant because both the average and the root mean square value of the current flowing through the bridge is constant. The loss created by the forward diode $D_{S 5}$ and the shunt MOSFET $S_{5}$ is small compared to the loss in the H-bridge and the diode bridge. The loss in the transformer is also small compared to the dominant losses which are losses in the $\mathrm{H}$ bridge and the diode bridge. As output power reduces, the duration in which the converter operates in shunt mode increases linearly. Even though the losses in the combination of forward diode $D_{S 5}$ and the shunt MOSFET $S_{5}$ and in the transformer decrease with the decrease of output power, their rate of decrease is smaller than the rate of increase in the switching loss of the primary side switches. Therefore, the total loss increases with lower output power. Thus, the efficiency drops.

The measured and calculated total loss are shown in Fig. 9. The power measurement is carried out by the PPA5530 precision power analyzer. The accuracy claimed by the manufacturer is $\pm 0.4 \%$ in the operation condition under test. It can be seen that the calculated total loss and the measured total loss match very well with each other. The largest discrepancy between the calculated loss and measured loss is $1.9 \mathrm{~W}$ at $222 \mathrm{~W}$ output power. This discrepancy constitutes $7.5 \%$ difference between the calculated and measured total loss and $0.85 \%$ difference between the calculated efficiency and the measured efficiency. One of the reasons that explain this discrepancy could be the accuracy of the precision power analyzer used. Nevertheless, the calculated total loss is able to predict the trend of the total loss. It is asymptotical to the measured total loss. It has been proven that the loss is approxi-

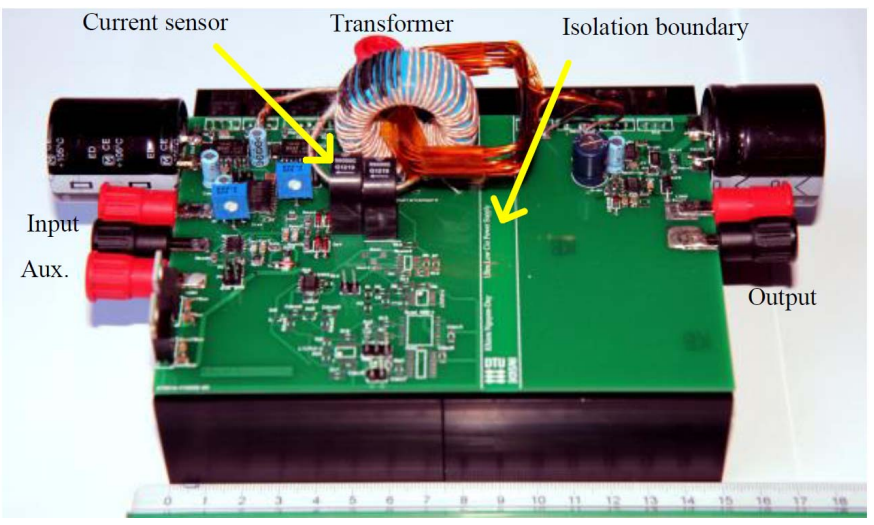

Fig. 5. A photo of the prototype of the proposed converter.

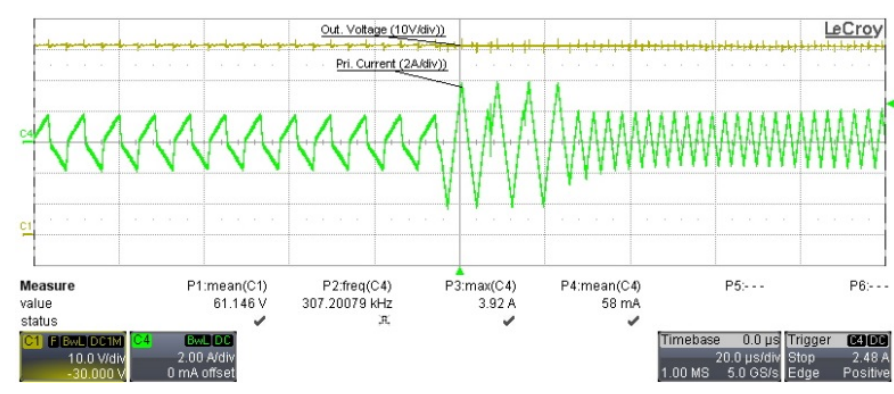

Fig. 6. Transient response from power mode to shunt mode. Top: output voltage (10V/div); bottom: inductor current (2A/div); time scale: $20 \mu \mathrm{s} / \mathrm{div})$.

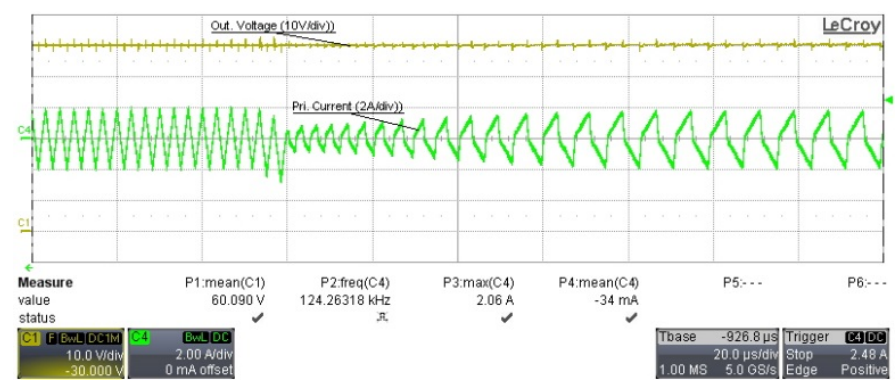

Fig. 7. Transient response from shunt mode to power mode. Top: output voltage (10V/div); bottom: inductor current ( $2 \mathrm{~A} / \mathrm{div})$; time scale: $20 \mu \mathrm{s} / \mathrm{div})$.

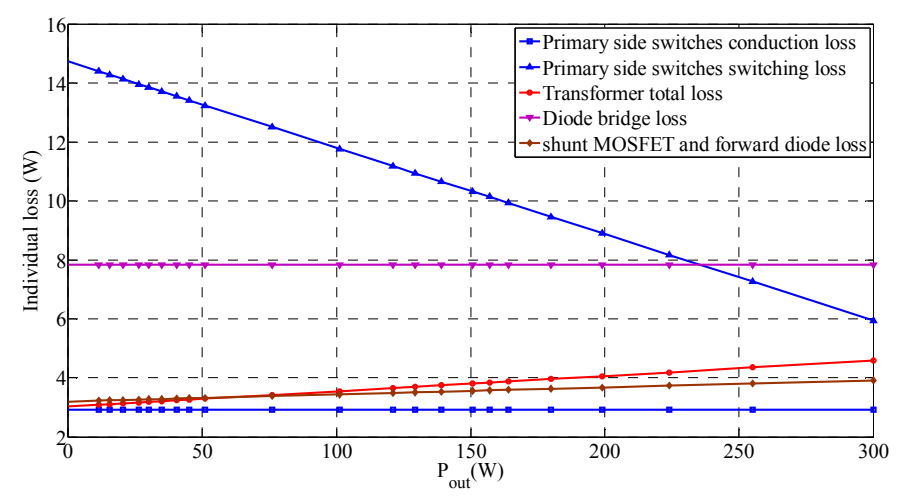

Fig. 8. Calculated breakdown loss. 


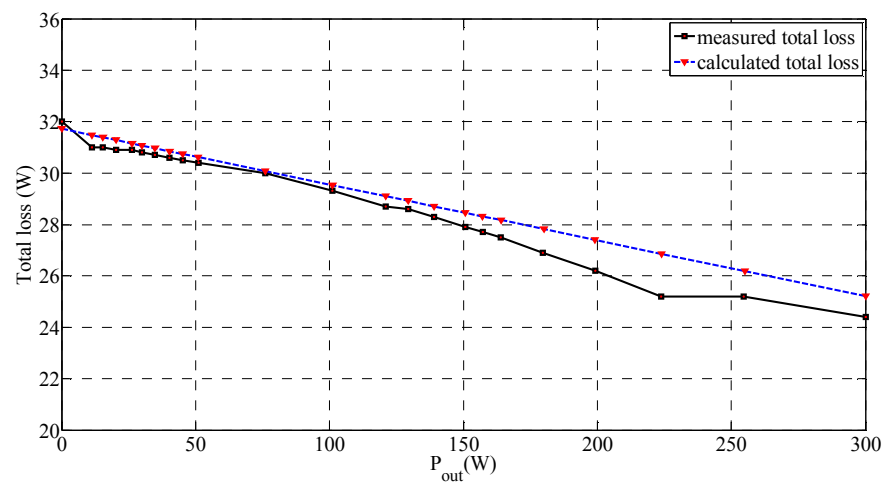

Fig. 9. Measured and calculated total loss.

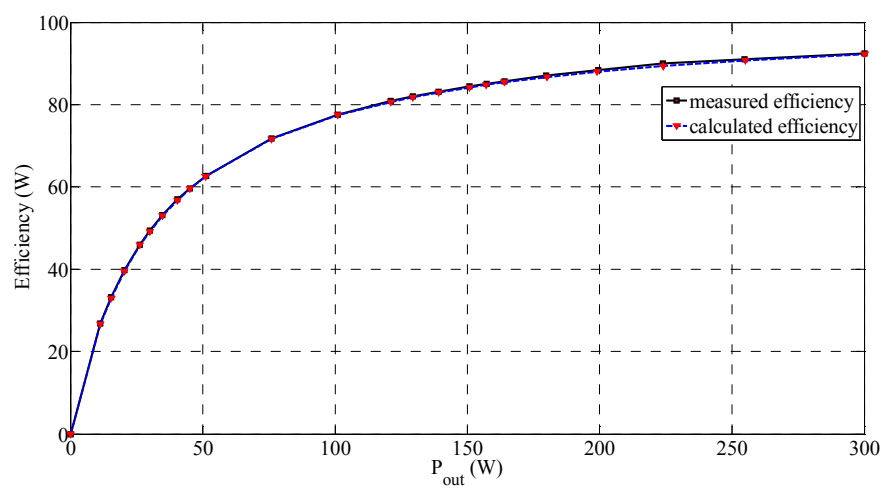

Fig. 10. Measured and calculated efficiency.

mated to be a linear combination of the shunt mode loss and power mode loss, as described in Section II.

The highest efficiency is $92.4 \%$, which is shown in Fig. 10. In general, the overall efficiency of the converter is satisfactory particularly in the range of $1 / 3$ of the nominal power to the nominal power. The efficiency in this range is from $77.5 \%$ to $92.4 \%$.

The calculated results show that the primary side switching loss is the predominant loss in the converter. Therefore, in order to further improve the efficiency of the converter, it is suggested that future design focus on reducing the switching loss on the primary side. It may be achieved by selection of different MOSFET part that is faster and hence yields lower switching loss.

\section{CONCLUSION}

This paper has dealt with the loss performance analysis of a novel power supply specially designed for ultra-fast tracking converters. The methods of calculating loss associated with each major physical device have been presented. The calculated total losses have been proven to match well with the measured data. The results of this analysis can serve as a guidance about which physical elements should be taken into account when the overall efficiency is of concern.

\section{REFERENCES}

[1] M. A. E. Andersen, "MOS gate driver circuit with extremely high galvanic isolation," in Proc. Eur. Conf. Power Electron. Appl., 1995, pp. $747-751$.

[2] K. Nguyen-Duy, L. P. Petersen, A. Knott, O. C. Thomsen, and M. A. E. Andersen, "Design of a 300-Watt isolated power supply with minimized circuit input-to-output parasitic capacitance," in Proc. 7th IET Int. Conf. Power Electron., Mach. Drive, pp. 1-6,April 8-10, 2014.

[3] K. Nguyen-Duy, Z. Ouyang, L. P. Petersen, A. Knott, O. C. Thomsen, and M. A. E. Andersen, "Design of a $300-\mathrm{W}$ isolated power supply for ultrafast tracking converters," in Early Access, IEEE Transactions on Power Electronics, vol., no. 99, pp.1,1.

[4] K. Nguyen-Duy, Z. Ouyang, A. Knott, and M. A. E. Andersen, "Minimization of the transformer inter-winding capacitance for modular stacking power supply applications," in Proc. 16th Eur. Conf. Power Electron. Appl., 26-28, Aug. 2014.

[5] (2014). VISHAY IRF840, SiHF840 Power MOSFET. [Online]. Available: http:/www.vishay.com/docs/91070/91070.pdf

[6] (2007, Oct.). VISHAY MBR10T100 High Performance Schottky Generation 5.0, 10A. [Online]. Available: http://www.farnell.com/ datasheets/39509.pdf

[7] (2011, Mar.). VISHAY IRF540, SiHF540 Power MOSFET. [Online]. Available: http:/www.vishay.com/docs/91021/91021.pdf

[8] (2006, Sep.). EPCOS Ferrites and accessories, Toroids R 30.5, R 34.0, R 36.0, Series/Type B64290. [Online]. Available: http://www.epcos. com/inf/80/db/fer_07/r_30.pdf

[9] (2006, Sep.). EPCOS Ferrites and accessories, SIFERRIT material N87. [Online]. Available: http://www.epcos.com/blob/528882/download/3/ pdf-n87.pdf

[10] J. Reinert, A. Brockmeyer, and R.W. De Doncker, "Calculation of losses in ferro- and ferrimagnetic materials based on the modified Steinmetz equation," IEEE Transactions on Industry Applications, vol. 37, no. 4, pp.1055-1061, Jul/Aug 2001.

[11] J. Reinert, A. Brockmeyer, and R.W. De Doncker, "Calculation of losses in ferro- and ferrimagnetic materials based on the modified Steinmetz equation," in Proc. 34th Ind. Appl. Conf., vol. 3, no., pp. 2087-2092, 1999.

[12]W. A. Roshen, "A practical, accurate and very general core loss model for nonsinusoidal waveforms," IEEE Transactions on Power Electronics, vol. 22, no. 1, pp. 30-40, Jan. 2007.

[13]M. Popescu, D. M. Ionel, A. Boglietti, A. Cavagnino, C. Cossar, and M. I. McGilp, "A general model for estimating the laminated steel losses under PWM voltage supply," IEEE Transactions on Industry Applications, vol. 46, no. 4, pp. 1389-1396, July-Aug. 2010.

[14]J. Muhlethaler, J. Biela, J. W. Kolar, and A. Ecklebe, "Improved coreloss calculation for magnetic components employed in power electronic systems," IEEE Transactions on Power Electronics, vol. 27, no. 2, pp. 964-973, Feb. 2012.

[15] A. Van den Bossche, V. C. Valchev, and G. B. Georgiev, "Measurement and loss model of ferrites with non-sinusoidal waveforms," in Proc. 35th Power Electron. Specialists Conf., vol. 6, no., pp. 4814-4818, 20-25 June 2004.

[16] P.-K, Lee, K.-C. Kuo, C.-J. Wu, Z.-T. Wong, and J.-T. Yen, "Prediction of iron losses using the modified Steinmetz equation under the sinusoidal waveform," in Proc. 8th Asian Control Conf. (ASCC), pp. 579_584, 15-18 May 2011. 